Western University Scholarship@Western

Electrical and Computer Engineering Publications Electrical and Computer Engineering Department

9-2016

\title{
International Comparison of Media Usage among University Students
}

Luiz Fernando Capretz

University of Western Ontario, lcapretz@uwo.ca

Gerd Gidion

Karlsruhe Institute of Technology

Follow this and additional works at: https://ir.lib.uwo.ca/electricalpub

Part of the Higher Education Commons, and the International and Comparative Education Commons

Citation of this paper:

4. Capretz L.F. and Gidion G., International Comparison of Media Usage among University Students, 19th International Conference on Interactive Collaborative Learning (ICL2016), pp. 1253-1260, Belfast, Northern Ireland, U.K., Springer, September 2016. 


\title{
International Comparison of Media Usage among University Students
}

\author{
Luiz Fernando Capretz ${ }^{1}$ and Gerd Gidion ${ }^{2}$ \\ ${ }^{1}$ Western University, London, Ontario, Canada \\ lcapretz@uwo.ca \\ ${ }^{2}$ Karlsruhe Institute of Technology, Karlsruhe, Germany \\ gerd.gidion@kit.edu
}

\begin{abstract}
A survey on media usage was conducted at Western University, followed by similar surveys in Germany, Spain and Thailand. It seems that the usage of IT-devices is more popular in Thailand and Germany than in Canada. The use of social network related applications in academia seems to be more common in Thailand compared to Canada and Germany. The competitiveness of the Internetbased market of academic education might be more intensive in Canada because of the proximity of the U.S. market. An international comparison is, nevertheless, problematic, because the circumstances are really diverse and in constant change. Future plans involve conducting a comparative global media survey in the area of higher education.
\end{abstract}

Keywords: Media Usage Comparison, Media in Education, Educational, eLearning, Technology-Enhance Learning

\section{Introduction}

The integration of IT media and services in higher education has led to substantial changes in the ways in which both students and instructors study, learn, and teach (Johnson et al. 2014; Carapucu and Capretz, 2012). Accordingly, surveys of students' and instructors' media usage habits have been conducted in Canada, Germany, Spain, and Thailand. These surveys purport to measure the extent to which media services are used in teaching and learning as well as to assess changes in media usage patterns. In addition, the surveys comprise part of an international research program in which 20 universities from 10 countries are currently participating.

The survey tool was first developed in 2009 and used at Karlsruhe Institute of Technology (KIT) in Germany (Grosch and Gidion, 2011). During the course of 15 followup surveys that were administered on an international basis, the original survey underwent optimization, translation into several languages, and validation. The data for this survey was collected online using a well-established online survey tool called Unipark.

In 2013-2014, the survey was administered at Western University to undergraduate students and faculty members (Gidion et al., 2016; Gidion et al., 2014a; Gidion et al., 
2014b; Gidion et al., 2013). The instructor survey, which resembles the student questionnaire, intends to compare the media usage of students and instructors by examining possible divergences in media culture that may create problems in the use of media for studying and teaching.

There is no doubt, however, that the integration of IT media and services in higher education appears to have led to substantial changes in the ways in which students study and learn. Higher education institutions are cautious about investing in programs to provide students with mobile devices for learning due to the rapidly changing nature of technologies (Alrasheedi and Capretz, 2013a). The acceptance of technology-enhanced education by students has increased in recent years, but not all services are equally accepted (Ali et al., 2014). It has become clear that simply using media and adopting elearning does not necessarily make a difference in student learning (Alrasheedi and Capretz, 2013b). Rather, pedagogy and the quality of the services are key factors for the effective use of technology (Ali et al., 2012).

\section{Research Methodology}

The surveys focused primarily on the media usage habits of students. Based on an assessment of the way in which media use relates to teaching and learning, the identification of trends provides an evidence base upon which more reliable predictions can be made about future trends of media usage in higher education.

The surveys were anonymous and consisted of 150 items measuring frequency of media usage and user satisfaction with 53 media services, including:

- Media hardware such as Wi-Fi, notebooks, tablet computers, desktop computers, and smartphones.

- Information services, such as Google search, Google Books, library catalogues, printed books, e-books, printed journals, e-journals, Wikipedia, open educational resources, and bibliographic software.

- Communication services, such as internal and external e-mail, Twitter, and Facebook.

- e-Learning services and applications, such as learning platforms and wikis.

Additional variables were also evaluated such as some aspects of learning behavior, media usage in leisure time, educational biography, and socio-demographic factors, as displayed in Fig.1.

\section{$3 \quad$ Results and Discussions}

The survey in North America followed the same concept as surveys in Europe and Asia. An international comparison is, nevertheless, problematic, because the circumstances are really diverse and in dynamic change. In addition to that, the trends could just be interpreted if repeated surveys have been conducted. So it is risky to answer questions about international similarities and differences, but some of the results can be documented in four parts: 
3.1 Selected items concerning the usage frequency of social network applications.

3.2 Selected items concerning the frequency of printed vs electronic media usage.

3.3 Selected items concerning the frequency of internal vs external media.

3.4 Selected items concerning the frequency of e-Learning applications usage.

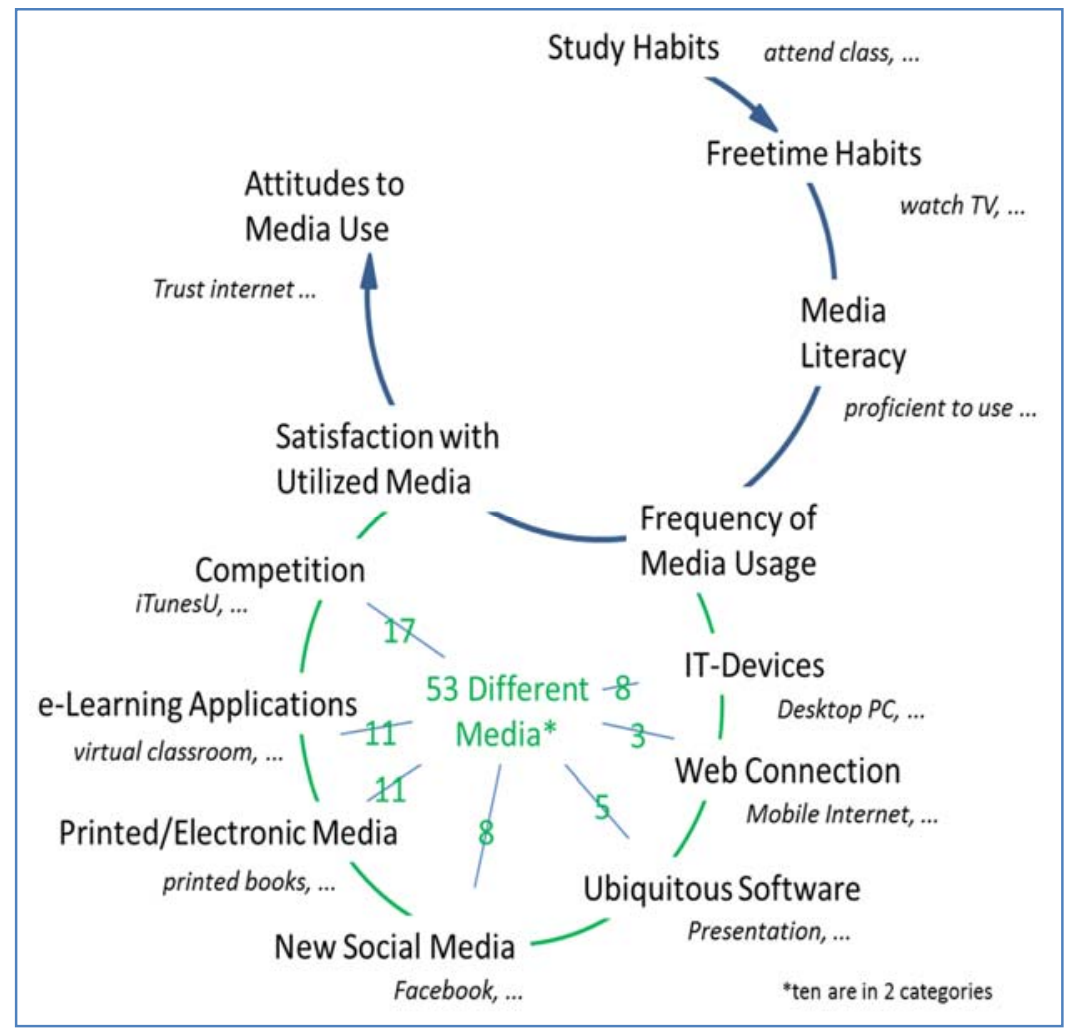

Fig. 1: Schematic display of the categories of the surveyed items

\subsection{Frequency of Usage of Social Networks Related Applications}

The utilization of Google search seems to be prevalent in all cases, and Wikipedia has a certain relevance on a lower, but also remarkable level in the survey results from all 4 universities - slightly more in the German and the Thai case. The results concerning the usage of video sharing websites like YouTube show a higher value in Thailand, followed by Spain and Canada, the lowest value in the German case, as depicted in Fig. 2 . 


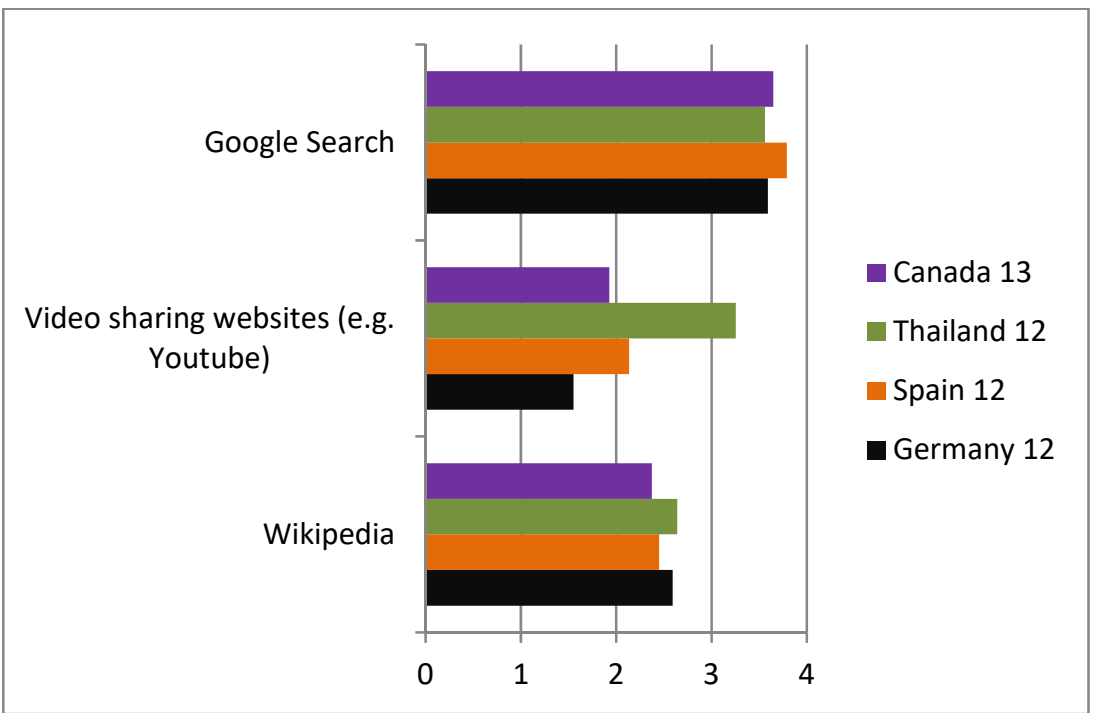

Fig. 2: Students from 4 selected universities: one each in Canada (valid $n=985$ ), Germany (valid $n=1236$ ), Spain (valid $n=981$ ), and Thailand (valid $n=968$ ), answer the question: How often do you use the following for learning/studying?), the question was rated on a five-point Likert scale with the following choices: "never" $(0)$, "rarely" (1), "sometimes" (2), "often" (3), and "very often" (4) (or equivalent; the figure shows the means of all those who answered these questions.

\subsection{Frequency of Printed vs Electronic Media Usage}

Looking at the results from the 4 universities, a few items from the group of printed vs electronic media usage might be interesting for the similarity or difference between the international locations. The Canadian case came to lower usage frequency values for "printed handouts from your instructor", "printed books", "e-books" and "print-versions of academic periodicals/journals", but higher values for "e- versions of academic periodicals/journals". Thai students seem to use e-books and print-versions of academic periodicals/journals more frequently than students in the other three cases. The German students show the lowest result of these four universities in the item "e- versions of academic periodicals/journals". Fig. 3 display more detailed results for this question. 


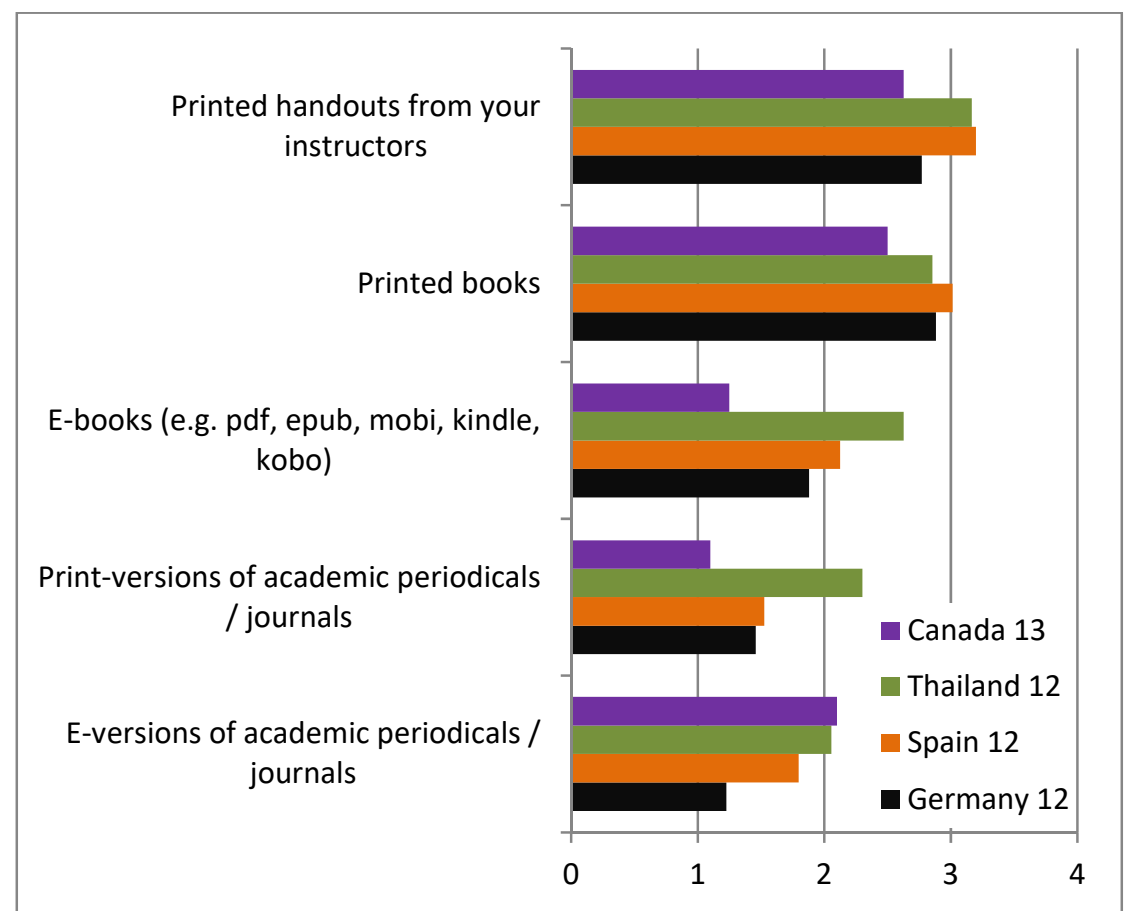

Fig. 3: Students from 4 selected universities: one each in Canada (valid $n=985)$, Germany (valid $n=1236$ ), Spain (valid $n=981$ ), and Thailand (valid $n=968$ ), answer the question: How often do you use the following for learning/studying?), the question was rated on a five-point Likert scale with the following choices: "never" (0), "rarely" (1), "sometimes" (2), "often" (3), and "very often" (4) (or equivalent; the figure shows the means of all those who answered these questions

\subsection{Frequency of University-Internal vs External Media}

Concerning the usage frequency of universities own vs external media services it might be interesting to look at three items that stand for the different sources. Online material (lecture notes) and/or scientific articles from your instructors are stated to be more frequently used than the other two items, "recorded lectures (audio, video)" - that might come from internal or external sources - and "online materials from other universities (e.g., iTunesU, Coursera, MIT Opencourseware)", with a somewhat higher value in Canada and Spain compared to Thailand and Germany. Recorded lectures seem to be more common in Thailand, the same for online materials from other universities, which are (surprisingly) at the moment less often used in Canada than at the other three involved universities, as shown in Fig. 4. 


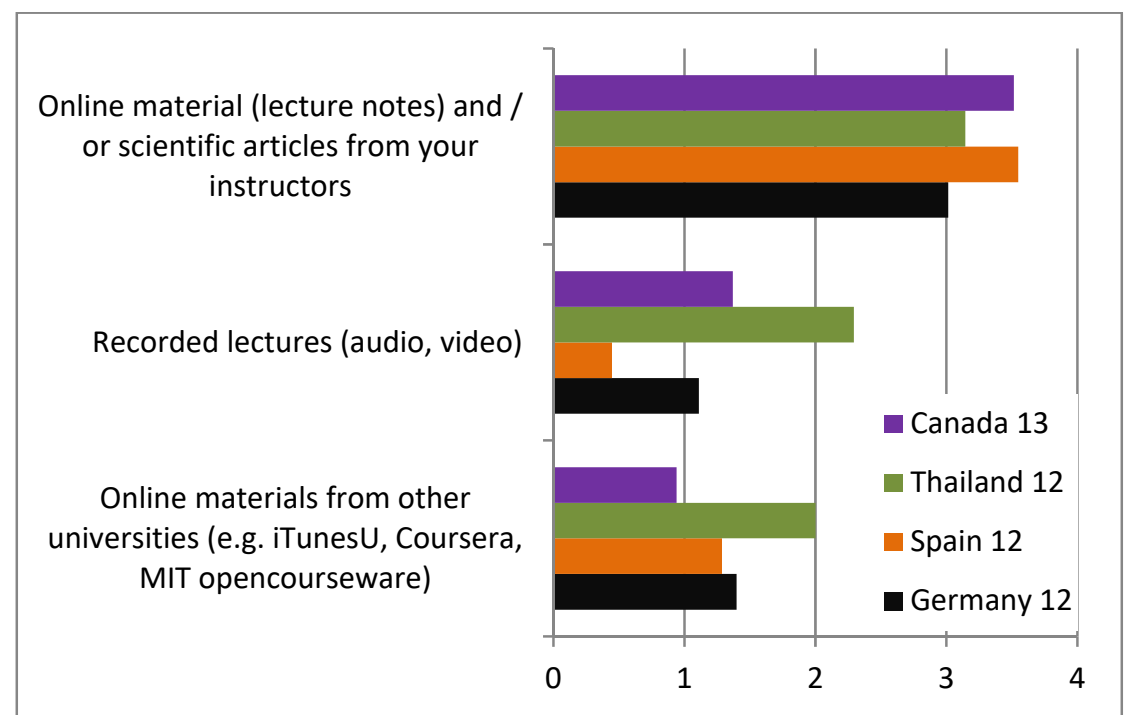

Fig. 4. Students from 4 selected universities: one each in Canada (valid $n=985$ ), Germany (valid $n=1236$ ), Spain (valid $n=981$ ), and Thailand (valid $n=968$ ), answer the question: How often do you use the following for learning/studying?), the question was rated on a five-point Likert scale with the following choices: "never" $(0)$, "rarely" (1), "sometimes" (2), "often" (3), and "very often" (4) (or equivalent; the figure shows the means of all those who answered these questions

\subsection{Frequency of e-Learning Application Usage}

Looking at the means of four involved universities, it can be stated that university websites are slightly more frequently used in the German university, followed by the Spanish and Thai and with a distance by the Canadian university, as presented in Fig. 5. The usage frequency of the Learning Management System is higher in the Canadian case, the Thai University shows the lowest frequency usage value in this item. There it seems to be more common - in comparison to these three other institutions - to utilize eLearning applications as a part of a course and wikis with active participation as part of a course. 


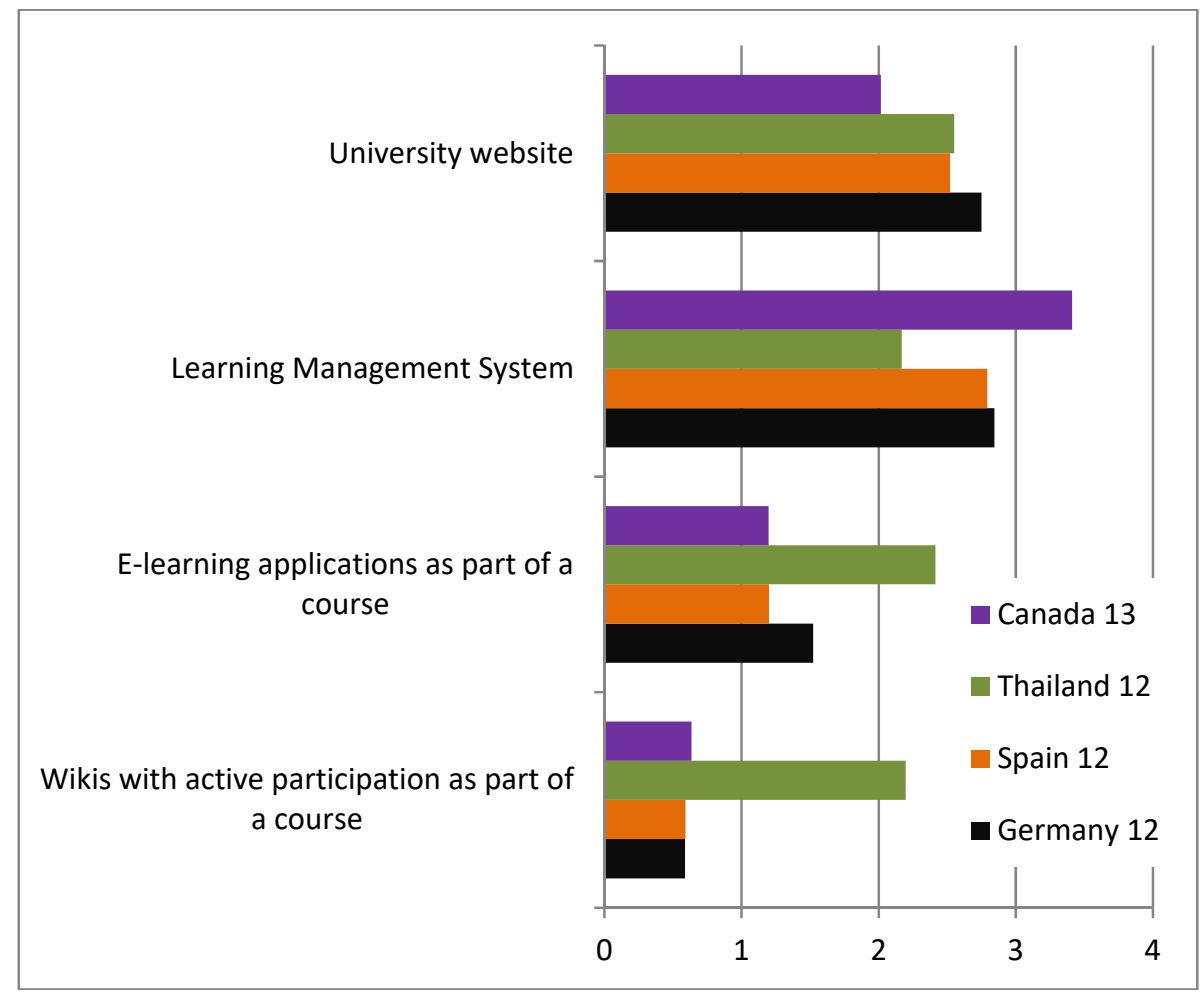

Fig. 5: Students from 4 selected universities: one each in Canada (valid $n=985)$, Germany (valid $n=1236$ ), Spain (valid $n=981$ ), and Thailand (valid $n=968$ ), answer the question: How often do you use the following for learning/studying?), the question was rated on a five-point Likert scale with the following choices: "never" $(0)$, "rarely" (1), "sometimes" (2), "often" (3), and "very often" (4) (or equivalent; the figure shows the means of all those who answered these questions.

\section{References}

Johnson, L., Becker, S.A., Estrada, V. \& Freeman, A.: NMC Horizon Report: Higher Education Edition, New Media Consortium: Austin, Texas (2014)

Dahlstrom, E.: ECAR Study of Undergraduate Students and Information Technology, EDUCAUSE Center for Applied Research: Louisville, CO, USA, http://net.educause.edu/ir/library/pdf/ERS1208/ERS1208.pdf (2012)

Capuruco, R.A.C. and Capretz, L.F.: Building Social-Aware Software Applications for the Interactive Learning Age, Interactive Learning Environments, 17(3):241-255 (2009) 
Grosch, M. \& Gidion, G.:, Mediennutzungsgewohnheiten im Wandel (German). Ergebnisse einer Befragung zur studiumsbezogenen Mediennutzung, KIT Scientific Publishing, http://digbib.ubka.uni-karlsruhe.de/volltexte/1000022524 (2011)

Gidion, G., Capretz, L.F., Meadows K. \& Grosch. M.: Trends in Students Media Usage, $16^{\text {th }}$ International Conference on Computational Science and Its Applications (ICCSA), Gervasi O. et al. (Eds.), LNCS 9786, DOI: 10.100/978-3-319-42085-1 38, pp.491-502 Springer Switzerland (2016)

Gidion, G., Capretz, L.F., Meadows K. \& Grosch. M.: Media Usage in Post-Secondary Education and Implications for Teaching and Learning, EAI Endorsed Transactions on e-Learning, 14(3):1-17, article e3, DOI: 10.4108/el.1.4.e3, European Union Digital Library (2014a)

Gidion, G., Capretz, L.F., Grosch, M. \& Meadows, K.: Are Students Satisfied with Media: A Canadian Cases Study, Bulletin of the IEEE Technical Committee on Learning Technology, 16(1):6-9 (2014b)

Gidion G., Capretz, L.F., Grosch, M. \& Meadows, K.: Media Usage Survey: How Engineering Instructors and Students Use Media, Proceedings of the Canadian Engineering Education Association Conference (CEEA'13), pp. 1-5 (2013)

Alrasheedi, M. \& Capretz, L.F.: A Meta-Analysis of Critical Success Factors Affecting Mobile Learning, Proc. of IEEE International Conference on Teaching, Assessment and Learning for Engineering (TALE), Bali, Indonesia, pp. 262-267, IEEE Press, (2013a)

Ali, A. Alrasheedi, M. Ouda A. \& Capretz, L.F.: A Study of the Interface Usability Issues of Mobile Learning Applications for Smartphones from the User's Perspective, International Journal on Integrating Technology in Education, 3(4):1-16, DOI: 10.512/ijite.2014.3401 (2014)

Alrasheedi, M \& Capretz, L.F.: An M-Learning Maturity Model for the Educational Sector, 6th Conference of MIT Learning International Networks Consortium (MIT LINC), Boston, MA, pp. 1-10, (2013b)

Ali, A., Ouda, A. \& Capretz, L.F.: A Conceptual Framework for Measuring the Quality Aspects of Mobile Learning, Bulletin of the IEEE Technical Committee on Learning Technology, 14(4):31-34, IEEE Press (2012) 